\title{
Projeto interdisciplinar de estudo e conservação da série "Retirantes" de Candido Portinari no Museu de Arte de São Paulo
}

\author{
Sofia Hennen Rodriguez, Aline Assumpção, Pedro Herzilio Ottoni Viviani de Campos, Bianca \\ Gonçalves, Erick Santos de Jesus, Elizabeth Alfredi de Mattos Kajiya, Fábio Luchiari, Márcia de \\ Almeida Rizzutto, Florence White de Vera, Cecilia Winter
}

\begin{abstract}
Resumo: "Retirantes", “Criança Morta” e "Enterro na Rede" são três pinturas a óleo, pintadas em 1944 pelo reconhecido artista brasileiro Candido Portinari. As três pinturas representam cenas da miséria gerada pelas migrações durante as secas no nordeste brasileiro. As três pinturas entraram para a coleção do museu como um conjunto em 1948. Devido às diferentes historias materiais e restaurações passadas, as pinturas apresentavam distintos estados de conservação. Foi organizado um projeto interdisciplinar com curadores, conservadores e cientistas, com o fim de estudar e restaurar cada uma das pinturas. A imagiologia e a caracterização material foram essenciais para justificar o tratamento proposto, que se realizou com a intenção de estabilizar as alterações presentes e recuperar a homogeneidade estética das três pinturas, permitindo uma exposição coerente do conjunto novamente.
\end{abstract}

Palavras-chave: pintura modernista, portinari, conservação, técnica pictórica, imagiologia, XRF, Raman, MASP

\section{Proyecto interdisciplinar de estudio y conservación de la serie "Retirantes" de Candido Portinari en el Museo de Arte de São Paulo}

\begin{abstract}
Resumen: "Retirantes", “Criança Morta” $y$ “Enterro na Rede" son tres pinturas a óleo, pintadas en 1944 por el reconocido artista brasileño Candido Portinari. Las pinturas representan la pobreza y la emigración del pueblo del noreste brasileño. Las tres pinturas entraron como un conjunto en la colección del museo en 1948. Debido a las diferentes historias materiales y restauraciones pasadas, las pinturas presentaban distintos estados de conservación. Se organizó un proyecto interdisciplinario con curadores, conservadores y científicos con el fin de estudiar y restaurar cada una de las pinturas. La imagenología y la caracterización material fueron esenciales para justificar el tratamiento propuesto, que se realizó con la intención de estabilizar las alteraciones presentes y recuperar la homogeneidad estética de las tres pinturas, permitiendo una exposición coherente del conjunto nuevamente.
\end{abstract}

Palabras clave: pintura modernista, portinari, conservación, técnica pictórica, imagenología, XRF, Raman, MASP

\section{An interdisciplinary project of study and conservation of Candido Portinari's "Retirantes" ensemble at Sao Paulo Museum of Art}

Abstract: "Retirantes", "Criança Morta" and "Enterro na Rede" are three oil paintings, painted in 1944 by Candido Portinari, a renowned Brazilian artist. The three paintings portray the poverty and emigration originated by the droughts of the Brazilian northeastern regions. The three paintings entered the museum's collection in 1948, as an ensemble. Due to different material histories and past restorations, the paintings presented distinct conservation states. An interdisciplinary project with curators, art conservators, and scientists was organized with the intention of studying and conserving each one of the paintings. Technical imaging and material characterization were essential to justify the proposed treatment, which was performed with the intent of ensure the stability of the alterations presented and recovering the aesthetical homogeneity of the three paintings, allowing a coherent exhibition of the ensemble again. 


\section{Introdução}

O Museu de Arte de São Paulo Assis Chateubriand (MASP) foi fundado em 1947, na sede dos Diários Associados pelo empresário e jornalista Assis Chateaubriand (1892-1968), com a ajuda do crítico de arte e galerista italiano Pietro Maria Bardi (1900-1999), primeiro diretor do MASP. Parte relevante do acervo do museu foi construída durante o período de pós-guerra, entre 1947 e 1960, quando foram adquiridas importantes pinturas europeias (atualmente, o museu possui a maior coleção de arte europeia da América Latina). Em 1968, a sede do museu foi transferida para o icônico prédio modernista de vidro e concreto, da arquiteta italiana Lina Bo Bardi (1914-1992), especialmente construído para receber a coleção. A arquiteta não só concebeu o prédio, mas também idealizou uma forma original de expor as obras, suspendendo as pinturas em cavaletes de vidro; trabalho expositivo que é a marca do museu (Pedrosa e Proença 2015; Gorini 2017). Desde a criação do museu, a coleção foi se enriquecendo com arte brasileira e contemporânea, adquirindo obras dos artistas brasileiros mais importantes da época, tais como Candido Portinari (1903-1962). Atualmente, o museu possui cerca de 12 mil obras, sendo uns dos museus mais importantes do Brasil e de América Latina.

O conjunto "Retirantes" (também chamado "Emigrantes") era inicialmente composto de cinco pinturas a óleo sobre tela de grandes dimensões: "Retirantes", "Enterro na Rede", "Emigrantes" e duas versões de "Criança Morta", pintadas entre 1944 e 1945 por Candido Portinari. Em 1946, as cinco obras são expostas na Galerie Charpentier em Paris. Uma das versões de "Criança Morta" é adquirida pelo Museu de Arte Moderna de Paris (MAM Paris) (MASP 2008). As obras "Retirantes", "Enterro na Rede" e a outra versão de "Criança Morta" [figura 1] entram para o acervo do MASP, em 1948. O destino da obra "Emigrantes" é desconhecido.

As obras do MASP foram selecionadas por Pietro Maria Bardi no ateliê do artista, para serem adquiridas por Assis Chateubriand, antes da abertura do museu, já com intenção de serem expostas juntas. Bardi (1985: 2) comenta que Chateubriand, "incentivador" do Portinari, deu "carta branca" para investir em obras do artista. Ele continua:

A aquisição mais notável foi a do 'Tríptico dos Retirantes'. Visitando e conversando com Candinho apreendia seu espírito de dedicação e consideração para com os menos favorecidos, seu desgosto ao saber dos sofrimentos, das pessoas 'esfrangalhadas', das coisas 'frágeis e pobres': um ânimo altruísta de constante vibração. Um dia me mostrou o 'Tríptico', que estava escondido atrás de um grupo de telas, e me narrou patéticos episódios, dandome um panorama da vida no campo: '- Quis lembrar. Pode ver a dor me dominando...' concluía ele com gestos de perplexa e desconsolada tristeza, movendo a cabeça, como que para se perguntar:'Mas é justo?' (Bardi 1985: 2).

Efetivamente, do ponto de vista temático, as obras abrangem o período em que a denúncia social, reflexo da precariedade da situação social brasileira, marcou a pintura de Portinari. As três pinturas representam cenas da miséria gerada pelas migrações durante as secas no nordeste brasileiro.

Do ponto de vista estilístico, as obras representam um momento importante no corpus artístico de Portinari, pois ilustram o momento em que este se liberta da influência cubista de Picasso, para dar lugar a um estilo mais pessoal e característico (MASP 2008).

No mesmo ano em que entram na coleção do MASP, as três obras são expostas no museu na exposição Portinari: exposição da sua obra de 1920 a 1948. Posteriormente, as três obras serão expostas juntas e separadamente, em inúmeras exposições nacionais e internacionais ao longo dos anos (Penna e Portinari 2004). Contudo, no decorrer dos anos, o conjunto foi separado, deixando "Enterro na Rede" armazenado na Reserva Técnica, o que prejudicou o diálogo inicial entre as três pinturas. Além disso, as obras passaram por diferentes intervenções de conservação e restauro, sem considerar a homogeneidade do conjunto.

Um projeto interdisciplinar foi organizado para estudar e tratar as três obras do MASP, com o objetivo, primeiro, de realizar um aprofundado estudo histórico, técnico e estilístico das pinturas, realizando diferentes análises materiais, pesquisa bibliográfica e na documentação do museu. A caracterização dos materiais e da tecnologia das pinturas era essencial, uma vez que, apesar de sua popularidade, existe pouca pesquisa realizada sobre a técnica de Portinari (Rosado et al. 2011; Rosado et al. 2014; Teixeira et al. 2011). Segundo, era necessário avaliar o estado de conservação das pinturas, mapeando todas as alterações presentes, para determinar um tratamento adequado e coerente, a fim de devolver a unidade estética e estrutural ao conjunto.

\section{Metodologia}

Foi reunida uma equipe de curadores e conservadores do museu, de dois conservadores externos com extensa experiência na obra do artista, e de pesquisadores do Instituto de Física da Universidade de São Paulo (IFUSP), encarregados de realizar as análises científicas.

Foi realizada a imagiologia multiespectral das três obras, incluindo fotografia com luz visível (LV), fotografias macro (MA), luz rasante (LR), luz transmitida (LT), fluorescência visível por iluminação Ultravioleta (LUV) e reflectografia no infravermelho (IRR). A fim de determinar os pigmentos utilizados pelo artista, foram realizadas análises espectroscópicas por fluorescência de raios X (XRF) e espectroscopia Raman.

Para as análises XRF, utilizou-se um sistema portátil constituído por um tubo de raios $\mathrm{X}$ modelo Mini-X da Amptek, com anodo de prata (com voltagem de $30 \mathrm{kV}$ e correntes de $5 \mu \mathrm{A}$ ) e um detector Si-PIN X-123 da Amptek. 
Nas análises por espectroscopia Raman foi utilizado um sistema portátil modelo EZ Raman-N dual, Enwave Optronics, empregando um laser de $785 \mathrm{~nm}$, com potencias da ordem de $20-300 \mathrm{~mW}$. Os espectros adquiridos possuem intervalo de medidas de 100 a 2200 cm-1 com resolução espacial de 6 cm-1. Na imagiologia usou-se uma câmera fotográfica digital modelo Canon EOS 5D Mark III, com lente objetiva de 24-105 $\mathrm{mm}, \mathrm{f} / 2.2-4$. Para a IRR, o equipamento utilizado foi a câmera Osiris, Opus Instruments, que possui um detector de InGaAs do tipo "array", que registra entre 900 e 1700 nm, com um conjunto de lentes de $150 \mathrm{~mm}$ e f/ 5,6-45.

Como fontes nas análises LV, LT e IRR, foram utilizadas duas lâmpadas alógenas de 1000 W. Para a técnica de LR, foi utilizado um conjunto linear de luz LED. Para as fotografias LUV, foram utilizados dois arranjos de lâmpadas UV, Philips HPW L 125 W T Ultraviolet.

Nas imagens LV, foi utilizada uma cartela de cor ColorChecker, X-Rite, para a correção do perfil de cores e balanço de branco. Todas as imagens obtidas foram editadas e ajustadas no programa Adobe Photoshop Lightroom CC, versão 8.4.

O processo de estudo e de tratamento das obras seguiu uma metodologia de trabalho específica predefinida, baseada na discussão interdisciplinar e no diálogo com profissionais de outras instituições. Para isso, duas apresentações foram organizadas: a primeira após o estudo preliminar, com o objetivo de compartilhar os resultados das análises e discutir a proposta de tratamento; a segunda após o tratamento, para avaliar e discutir os resultados das intervenções de conservação e restauro realizadas.

\section{Resultados}

\section{-Técnica pictórica}

As três telas são de fibras celulósicas - possivelmente algodão - em completa predominância, de ligamento tela/ tafetá, de tecelagem industrial, mas possuem densidades e espessuras diferentes. Ambas as telas de "Retirantes" e "Criança Morta" apresentam vários carimbos e inscrições nos versos referentes a exposições passadas. "Enterro na Rede" foi reentelada em 1969 (ver na seção seguinte), impedindo o acesso ao verso da tela original. No verso da obra "Retirantes", há um esboço de braço feito pelo artista, e alguns desenhos infantis, realizados por João Candido, filho do artista, de acordo com o próprio João [figura 1].

Tanto "Retirantes", como "Criança Morta", possuem uma preparação branca e fina, enquanto a preparação de "Enterro na Rede" é mais espessa e apresenta uma tonalidade cinza. As análises XRF e Raman mostraram a presença de uma mistura de carbonato de cálcio e branco de zinco na base de preparação das três telas [tabela 1].

Podemos observar, através das guirlandas de tensão e dos restos de preparação que se encontram presentes nas bordas, que a preparação foi aplicada em um chassi temporário, provavelmente maior do que o original. É possível que várias telas tenham sido preparadas no mesmo chassi, para depois serem recortadas nos formatos finais e esticadas nos chassis definitivos. No entanto, apenas o chassi de "Retirantes" parece ser original.

Em "Retirantes" e "Criança Morta", observa-se primeiro um desenho de carvão, realizado diretamente sobre a preparação, que aparece a olho nu em algumas zonas da pintura. Este desenho aparece sintético e rápido. Foi possível observar alguns reajustes pontuais realizados durante a pintura [figura 2]. Observa-se um segundo desenho, realizado com pincel e tinta a óleo preta - a base de preto de osso ou de marfim e óxido de ferro, segundo as análises XRF e Raman, que delineia as figuras e os objetos da composição com espontaneidade e força, e se mistura com as demais pinceladas da pintura. Este segundo desenho faz parte da composição final e não pode ser considerado como um desenho preparatório propriamente dito.

Na camada pictórica observam-se efeitos de estrutura em distintas regiões da pintura, criando diferentes contrastes: empastes e relevos importantes encontram-se especialmente nas cores brancas, nos personagens das três obras. Por outro lado, a camada pictórica pode ser bastante fina em determinadas regiões, como nos céus. Em algumas zonas das figuras a preparação foi deixada visível, revelando a textura da tela [figura 3].

A camada pictórica é ligeiramente granulosa na zona inferior, ao nível do chão. Areia ou terra foi integrada na preparação ou na camada pictórica, com o objetivo de criar uma certa porosidade, o que seria caraterístico da técnica do Portinari (Rosado et. al. 2014), que tenta imitar os efeitos da pintura mural mesmo nas suas obras sobre tela.

As pinceladas são firmes e seguras, de tamanhos e espessuras distintos. Em algumas zonas tem bastante densidade, em outras são 'secas', trazendo pouca matéria pictórica. Alguns traços foram realizados com espátula e alguns efeitos pictóricos foram obtidos com a ponta dos pinceis [figura 4].

No caso de "Enterro na Rede", a composição se destaca de "Retirantes" e de "Criança Morta", sendo mais densa, integralmente preenchida pelos elementos pictóricos, e tendo uma gama cromática mais quente. Tanto a execução das figuras, como a construção dos planos, é realizada de forma mais geométrica, lembrando o passado cubista do artista. Por fim, as pinceladas são mais espessas e intensas, especialmente nos contornos das figuras, dando um aspecto mais gráfico à pintura.

Percebe-se uma espontaneidade e rapidez de execução e um grande domínio da pintura na hora de criar efeitos pictóricos. Observa-se também o domínio na utilização das cores. Os pigmentos, que puderam ser caracterizados graças às análises XRF e Raman, encontram-se detalhados 


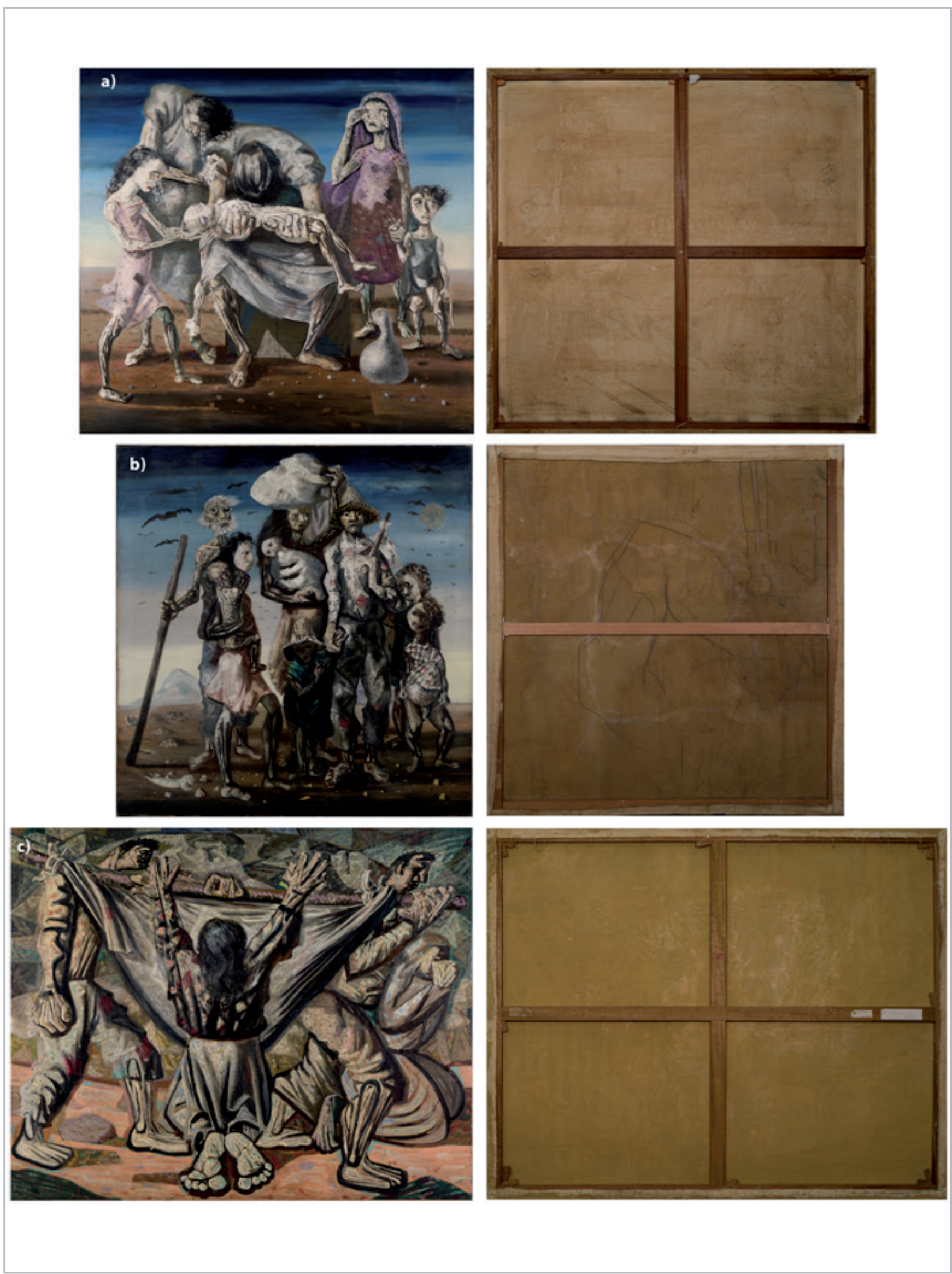

Figura 1.- Fotografia LV frente (esq.) e verso (dir.), antes do tratamento de conservação e restauro de: a) “Criança Morta”; b) “Retirantes”; c) "Enterro na Rede". Fotos: Pedro Campos/Elizabeth Kajiya/Márcia Rizzuto (IFUSP). 
Tabela 1.- Pigmentos encontrados por espectroscopias XRF e Raman. Fonte: Pedro. Campos/Elizabeth Kajiya/Márcia Rizzuto (IFUSP).

\begin{tabular}{|c|c|c|c|c|c|c|}
\hline Cor & XRF & Raman & Sugestão dos Pigmentos & Retirantes & $\begin{array}{l}\text { Criança } \\
\text { Morta }\end{array}$ & $\begin{array}{l}\text { Enterro na } \\
\text { Rede }\end{array}$ \\
\hline $\begin{array}{l}\text { Base de } \\
\text { reparação }\end{array}$ & $\mathrm{Zn}$ & $\mathrm{ZnO}, \mathrm{CaCO}_{3}$ & $\begin{array}{l}\text { Branco de zinco; Carbonato de } \\
\text { cálcio }\end{array}$ & $x$ & $x$ & $\mathrm{x}$ \\
\hline \multirow{3}{*}{ Branco } & $\mathrm{Pb}$ & $2 \mathrm{PbCO}_{3} \cdot \mathrm{Pb}(\mathrm{OH})_{2}$ & Branco de chumbo & $x$ & $x$ & $x$ \\
\hline & $\mathrm{Zn}$ & $\mathrm{ZnO}$ & Branco de zinco & $x$ & & $x$ \\
\hline & $\mathrm{Ti}$ & $\mathrm{TiO}_{2}$ (Anatase) & Branco de titânio & $x$ & $x$ & $x$ \\
\hline \multirow{3}{*}{ Preto } & $\mathrm{Ca}$ & C & Preto de Osso & $x$ & $x$ & $x$ \\
\hline & $\mathrm{Fe}$ & & Óxido de Ferro & $x$ & $x$ & $x$ \\
\hline & $\mathrm{Mn}$ & $\mathrm{C}_{17} \mathrm{H}_{16} \mathrm{~N}_{4} \mathrm{O}_{4}$ & Óxido de Manganês & $x$ & $x$ & \\
\hline \multirow{2}{*}{ Marrom } & $\mathrm{Fe}$ & & Óxido de Ferro & $x$ & $x$ & $x$ \\
\hline & $\mathrm{Mn}$ & & Óxido de Manganês & $x$ & $x$ & \\
\hline \multirow{2}{*}{ Ocre / Bege } & $\mathrm{Fe}$ & & Óxido de Ferro & $x$ & $x$ & $x$ \\
\hline & $\mathrm{Mn}$ & & Óxido de Manganês & $x$ & $x$ & \\
\hline Vermelho & $\mathrm{Cd}, \mathrm{Se}$ & $\mathrm{CdSe}(\mathrm{S})$ & Vermelho de Cádmio & $x$ & $x$ & $x$ \\
\hline Amarelo & - & $\mathrm{C}_{17} \mathrm{H}_{16} \mathrm{~N}_{4} \mathrm{O}_{4}$ & Amarelo Hansa & $x$ & & \\
\hline \multirow{2}{*}{ Verde } & $\mathrm{Cr}$ & & Óxido de Cromo & $x$ & $x$ & $x$ \\
\hline & $\mathrm{Cu}, \mathrm{As}$ & & Verde Esmeralda / Verde Scheele & $x$ & $x$ & \\
\hline \multirow{3}{*}{ Azul } & Co & & Azul de Cobalto & & & $x$ \\
\hline & $\mathrm{Co}, \mathrm{Sn}$ & $\mathrm{CoO} . \mathrm{nSnO}_{2}$ & Azul Cerúleo & $x$ & $x$ & \\
\hline & - & $\mathrm{Na}_{8-10} \mathrm{Al}_{6} \mathrm{Si}_{6} \mathrm{O}_{24} \mathrm{~S}_{2-4}$ & Lazurita / Ultramarino & $x$ & $x$ & $x$ \\
\hline \multirow{2}{*}{ Violeta } & $\mathrm{Mn}$ & & Violeta de Manganês & & & $\mathrm{x}$ \\
\hline & Co & & Violeta de Cobalto & & $\mathrm{x}$ & \\
\hline
\end{tabular}

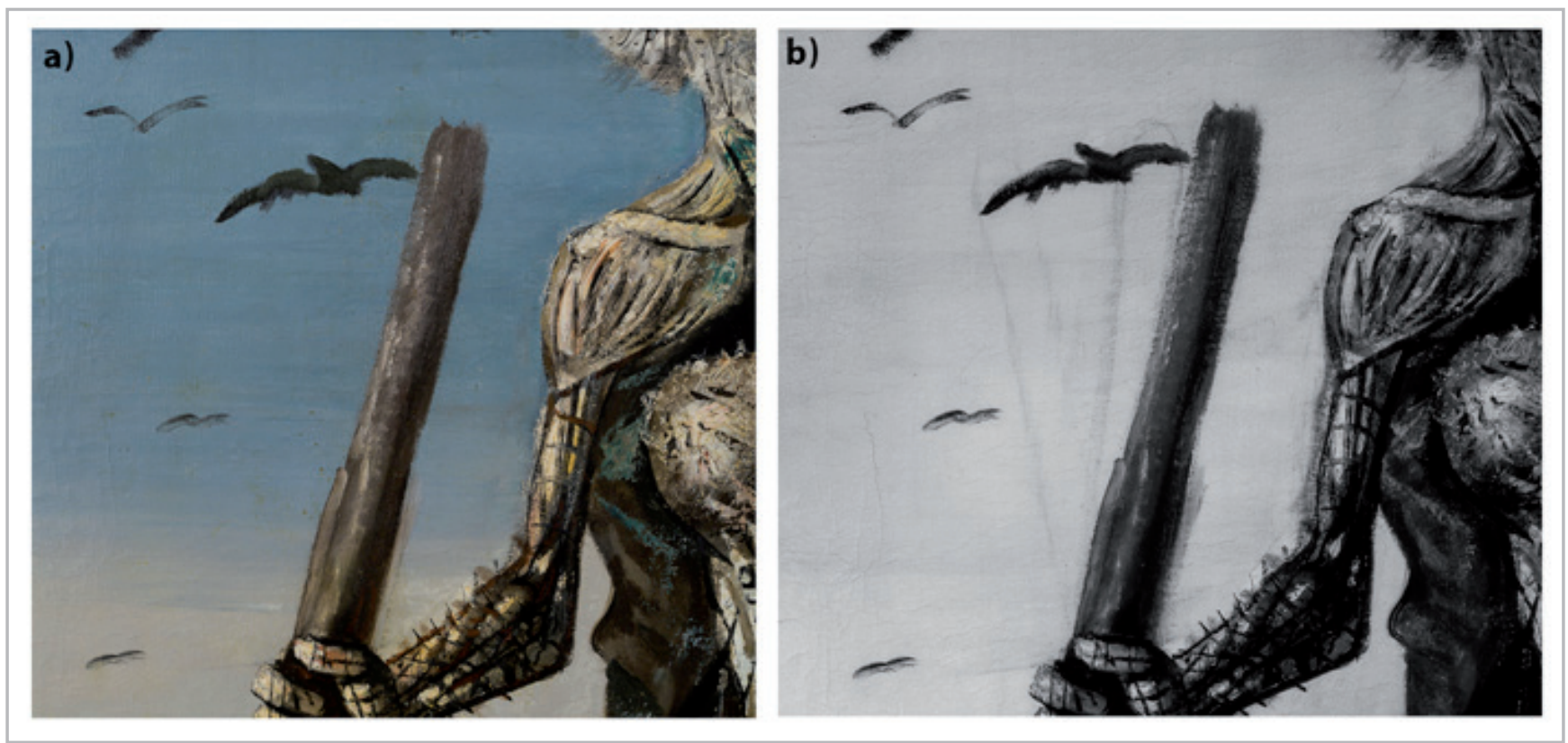

Figura 2.- Exemplo de uma mudança na composição de "Retirantes”: a) Fotografia LV; b) IRR. Fotos: Pedro Campos/Elizabeth Kajiya/Márcia Rizzuto (IFUSP). 

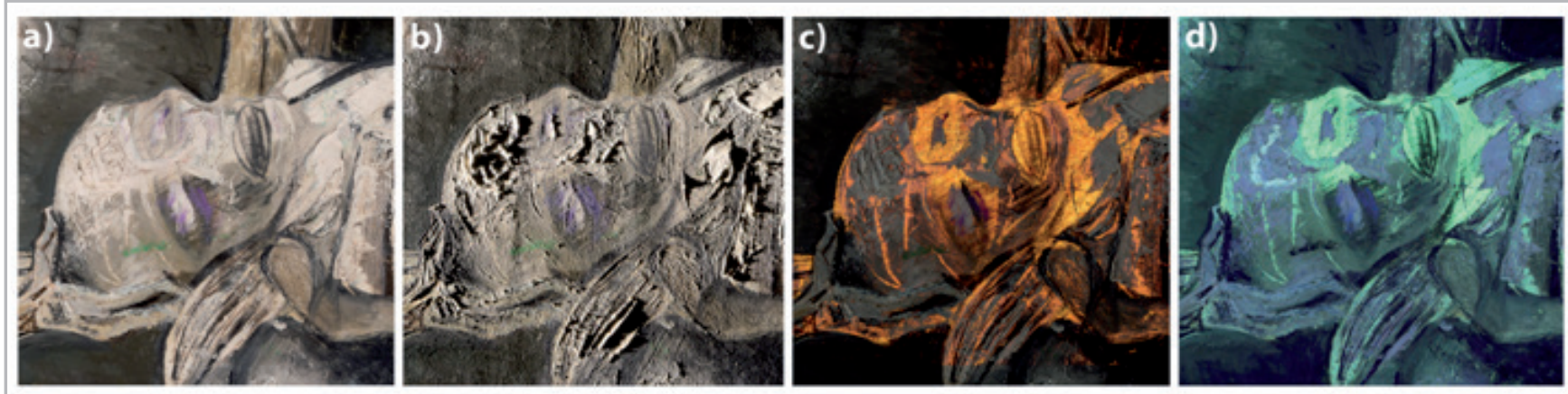

Figura 3.- Detalhes de zonas de preparação visíveis em “Criança Morta”: a) Fotografia LV; b) Fotografia LR; c) Fotografia LT; d) Fotografia LUV. Fotos: Pedro Campos/Elizabeth Kajiya/Márcia Rizzuto (IFUSP).

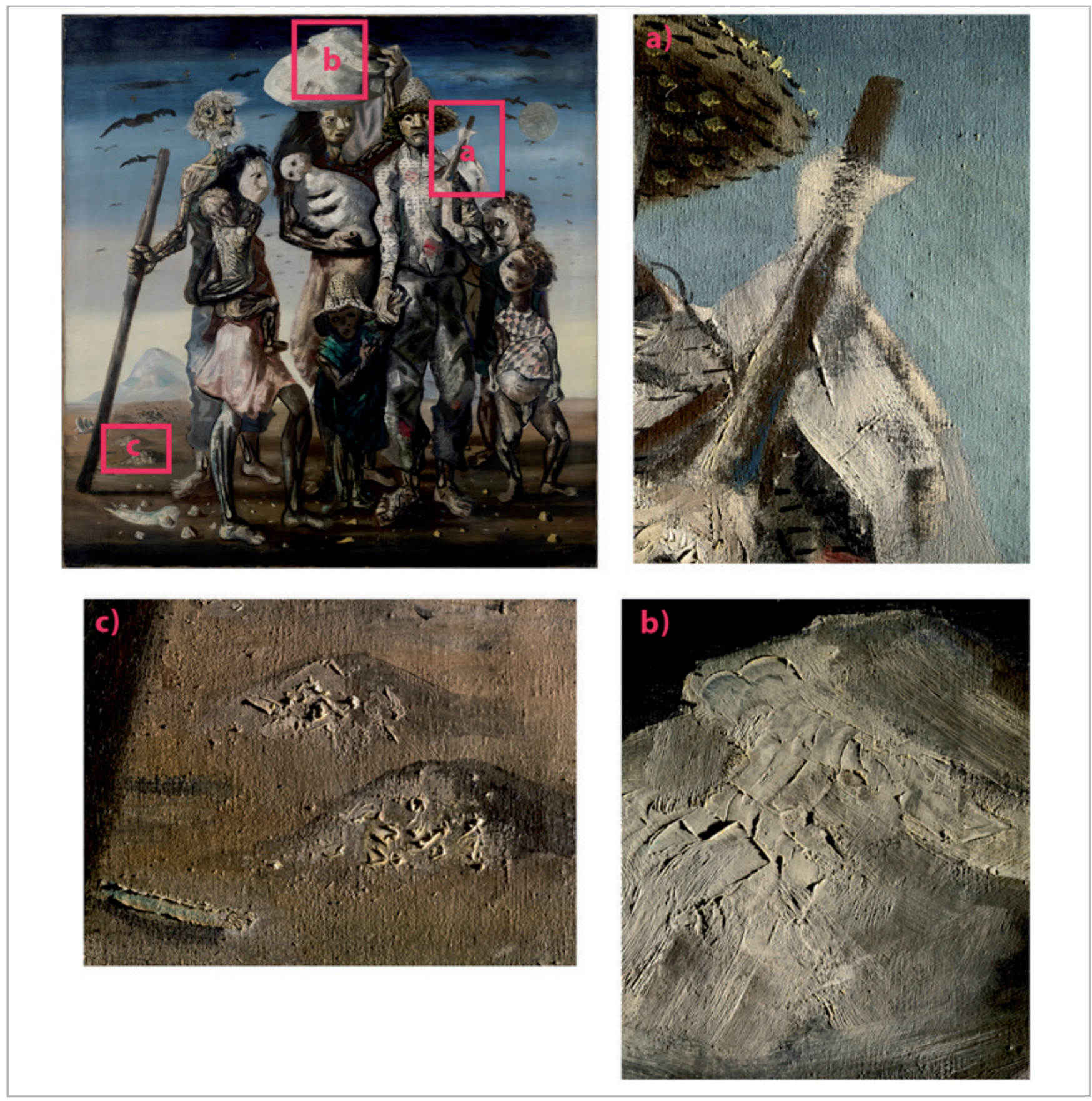

Figura 4.- Detalhes de "Retirantes": a) Fotografia LR de pinceladas secas; b) Fotografia LR dos traços realizados com espátula; c) Fotografia LR dos efeitos realizados com a ponta dos pinceis. Fotos: Pedro Campos/Elizabeth Kajiya/Márcia Rizzuto (IFUSP). 
na tabela 1. Observam-se alguns elementos interessantes, como a utilização de três brancos diferentes: branco de zinco, branco de titânio e branco de chumbo. O pintor parece ter explorado as distintas potencialidades dos brancos, tanto da pintura como da preparação, sobretudo na produção das figuras. Observa-se também que Portinari utilizou, por exemplo, distintos violetas, azuis, verdes e pretos para criar as variadas cores.

No canto inferior direito das três obras, observa-se a assinatura e a data.

\section{- História material}

A documentação do museu, incluindo cartas, fotografias e documentos antigos, permitiu traçar parte do passado material das três obras, o que foi em seguida confirmado pelas observações a olho nu e análises técnicas.

A respeito da obra "Criança Morta", um documento de 1991 relata um breve diagnóstico, uma proposta de tratamento e um orçamento (Brixa 1991), mas não foi encontrado nenhum relatório de tratamento, fotos ou outro tipo de registro das intervenções. É possível que tais documentos tenham se perdido ou que nunca tenham sido entregues ao museu. $\mathrm{O}$ documento descreve que "As bordas de tecido do suporte sofreram danos por ação de insetos, que atacaram o chassi original da obra, o qual teve que ser inutilizado. Observam-se ainda algum ressecamento das camadas pictóricas e pequenas lacunas". No documento, o restaurador propõe "colocar bordas de tensão de reforço com tiras de poliéster e adesivo sintético; consolidação, nivelamento e retoque das lacunas; limpeza da superfície; aplicação de uma camada protetora de cera microcristalina; e esticamento da tela num chassi novo" (Brixa 1991). As diferentes análises permitiram comprovar que as intervenções de restauro propostas foram efetivamente realizadas. Além disso, as fotografias LUV [figura 5] permitiram evidenciar que a limpeza foi seletiva, concentrando-se mais nas figuras e nas zonas claras, e parcialmente nas regiões próximas às margens superior e inferior da composição. Nestas últimas, foram observadas também veladuras aparentemente oleosas, provavelmente destinadas a dissimular manchas de ataques de fungos e outras alterações pontuais, como perdas e desgastes, mas não foi possível determinar se esta intervenção foi realizada em 1991 ou se tratava-se de uma intervenção mais antiga (talvez realizada pelo próprio artista posteriormente à finalização da obra).

Sobre a obra"Retirantes", um breve relatório de 1962 informa uma intervenção de restauro realizada na Bahia, quando a obra foi em empréstimo. No documento é descrito o estado da obra, que apresentava craquelês na camada pictórica "com risco iminente de perda", sujidade superficial e um verniz "deteriorado" (Rescala 1962). O restaurador descreve brevemente os processos realizados: "solidificação da camada de tinta com o respectivo fundo à tela (suporte) por meio de injeções generalizadas através o reverso da pintura (Processo Penderleith) para consolidá-la estruturalmente e impedir a continuação do craquelê. Limpeza da superfície da pintura e aplicação de verniz" (Rescala 1962).

Por último, os arquivos de "Enterro na rede" relatam pelo menos três intervenções de restauro. Um primeiro tratamento foi realizado em 1969: "o quadro foi reentelado com lona crua, forte e resistente, usando-se cola não aquosa, de cera virgem com breu 100:60. Em seguida foi esticado sobre um chassi reforçado de cedro com cruzeta" (Bettencourt 1969). O mesmo documento menciona que não foram aplicados retoques ou vernizes. No entanto, nenhum relatório de tratamento foi encontrado.

Em 1992, durante uma exposição em Zurique, é detectado um "descolamento da camada pictórica". É sugerido realizar uma fixação antes do retorno da obra, contudo esta intervenção também não é documentada.

Em 2012, são realizadas algumas intervenções pontuais emergenciais pela conservadora do museu, para preparar a obra para uma exposição na Coreia do Sul. Deste tratamento foram conservadas fotografias de registro e um relatório de restauro (Barbosa 2012). No relatório é explicado que o processo de envelhecimento da cera-breu provocou perda de aderência, resultando no descolamento da tela do suporte e deformações em forma de ondulações e bolhas, colocando em risco a integridade da obra. Uma intervenção no suporte é aconselhada, porém, só um tratamento de consolidação pontual da camada pictórica é realizado com Beva 371 a 20\% em tolueno (Barbosa 2012).

\section{- Estado de conservação}

Tratadas em momentos diferentes e com distintos níveis de intervenção e objetivos, as três obras encontravam-se em estados de conservação desiguais. Tendo sido restaurada mais recentemente, "Criança Morta" apresentava o melhor estado de conservação. O suporte apresentava muitas marcas de fungos distribuídas por toda a superfície da tela, causadas por um ataque biológico antigo, anterior a 1991 (Brixa 1991). Os microrganismos afetaram igualmente a camada pictórica através de manchas alaranjadas presentes nas bordas superior e inferior da composição. Retoques pontuais realizados em 1991 para dissimulá-las tornaramse, com o tempo, escuros e foscos (claramente visíveis nas fotografias UVL e a olho nu). Contudo, devido ao tamanho da obra e à sua localização nas bordas, não influenciavam a correta leitura da obra. As veladuras a óleo, mencionadas anteriormente, não suscitavam nenhuma alteração visual. Ao contrário, elas ajudavam na reintegração das pequenas perdas e desgastes antigos.

O aspecto ótico geral da obra encontrava-se bastante homogêneo, apesar da limpeza parcial e seletiva de 1991. Os restos de verniz antigo não influenciavam na tonalidade da composição. Contudo, o aspecto fosco criado pela cera microcristalina contrastava com o aspecto mais brilhante das outras duas obras da série. 
Em "Retirantes", o verso apresentava excesso de cera-resina, causado pela impregnação de 1962. Além disso, a tela estava levemente abaulada em alguns pontos por causa do chassi fixo, que não permitia uma adaptação da tensão.

Quanto a camada pictórica, craquelês antigos - já mencionados em 1962 - encontravam-se estáveis e não apresentavam riscos de desprendimento. Porém, em algumas áreas pareciam levemente levantados. Nos cantos da pintura tinham aparecido também craquelês de tensão.

Um excesso da cera-resina encontrava-se acumulado em diversas regiões da camada pictórica, dando um aspecto mais opaco, escuro e amarelado a estas zonas da composição.
O verniz aplicado em 1962 estava oxidado e irregular. As fotografias LUV ilustraram a presença de resíduos de um verniz mais antigo (possivelmente original) o que confirma uma limpeza superficial e parcial da obra, realizada no passado. As figuras humanas e as áreas com tinta branca, apresentavam uma maior remoção desse verniz, e resíduos nos relevos da pintura [figura 5]. O amarelecimento do verniz e da cera-resina, bem como o contraste entre as áreas brilhantes e opacas destas camadas, estavam dando um aspecto pouco homogêneo à pintura.

Na faixa horizontal central da obra, nas áreas do céu com coloração azul claro e branca, observaram-se alterações na pintura. Nestes locais, parecem ter ocorrido abrasões

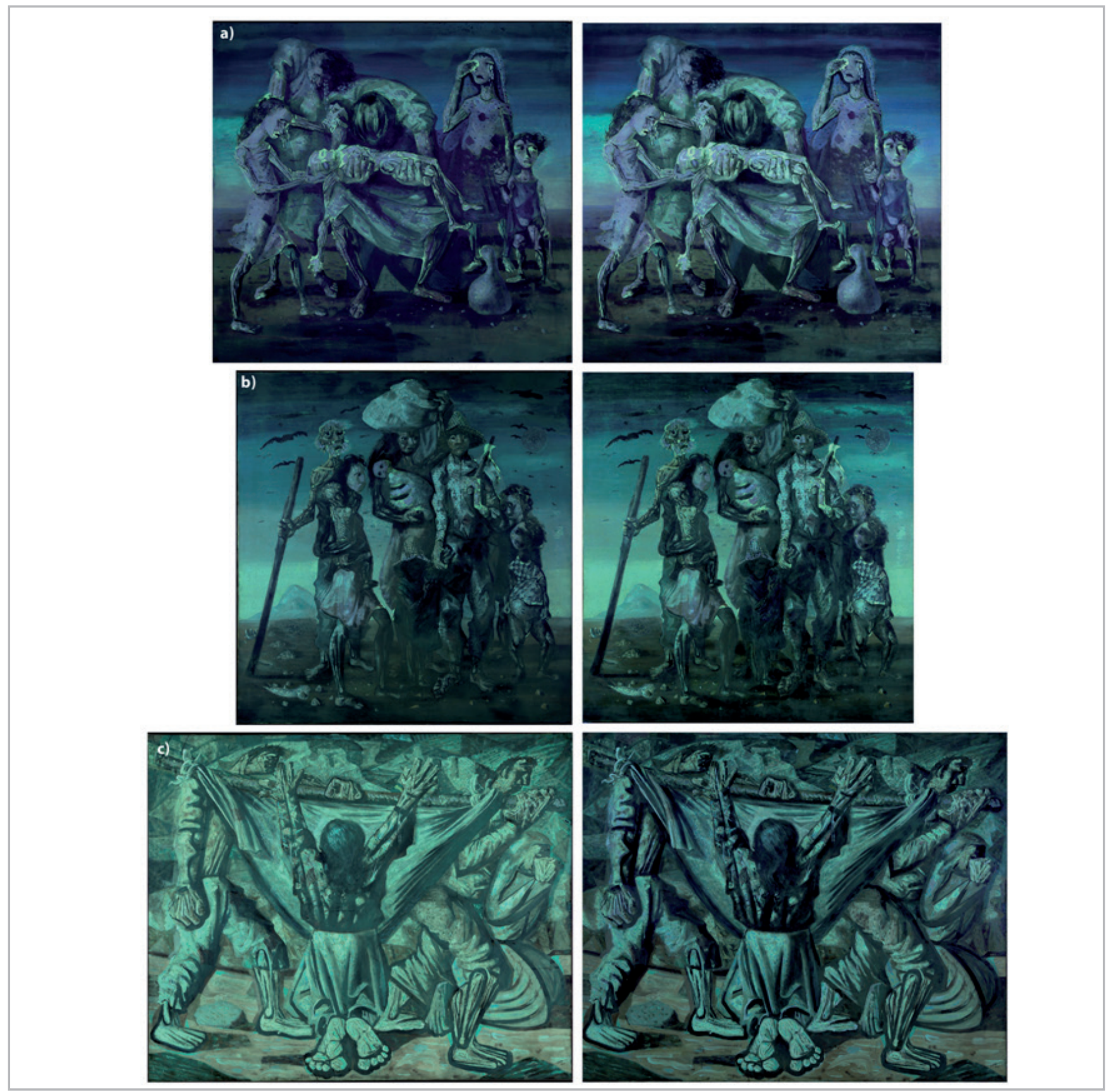

Figura 5.- Fotografias LUV antes da limpeza (esq.) e depois da limpeza (dir.) de: a) “Criança Morta”; b) “Retirantes"; c) “Enterro na Rede”. Fotos: Pedro Campos/Elizabeth Kajiya/Márcia Rizzuto (IFUSP). 


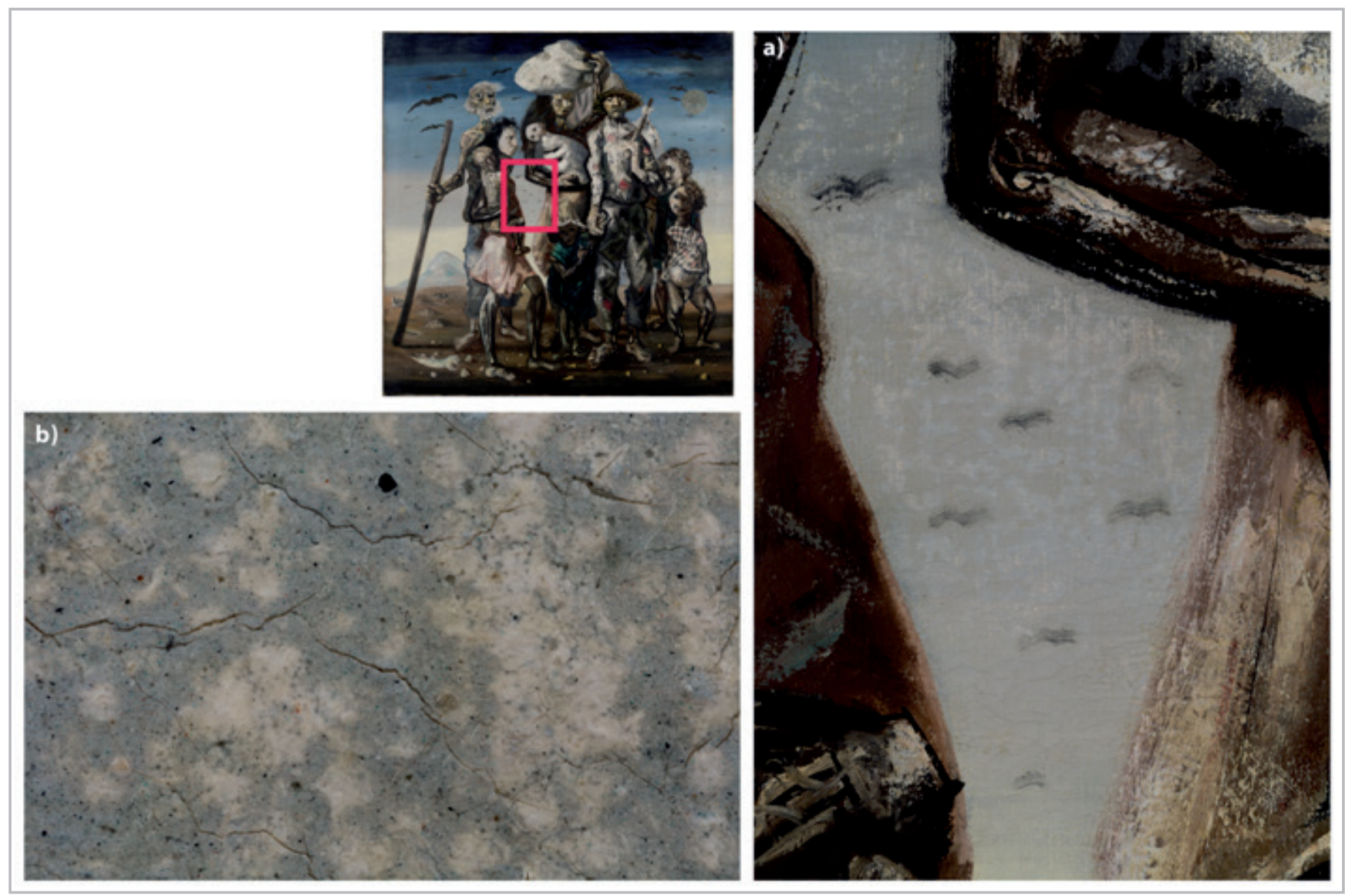

Figura 6.- Detalhe de uma zona de alteração da camada pictórica em “Retirantes": a) Fotografia LV; b) Macro LV. Fotos: Pedro Campos/ Elizabeth Kajiya/Márcia Rizzuto (IFUSP).

da camada pictórica, deixando parte da camada de preparação branca aparente [figura 6]. No quadrante superior esquerdo, na parte escura do céu, observou-se uma alteração similar. É bastante provável que estas zonas de branqueamento e abrasão das camadas de pintura superficiais tenham sido provocadas por uma limpeza agressiva no passado, utilizando métodos inadequados como soluções decapantes ou muito penetrantes, junto com uma ação mecânica insistente. Observaram-se também retoques anteriores visíveis nas imagens LUV e a olho nu, localizados nas laterais da pintura.

Um excesso da cera-resina encontrava-se acumulado em diversas regiões da camada pictórica, dando um aspecto mais opaco, escuro e amarelado a estas zonas da composição. O verniz aplicado em 1962 estava oxidado e irregular. As fotografias LUV ilustraram a presença de resíduos de um verniz mais antigo (possivelmente original) o que confirma uma limpeza superficial e parcial da obra, realizada no passado. As figuras humanas e as áreas com tinta branca, apresentavam uma maior remoção desse verniz, e resíduos nos relevos da pintura [figura 5]. O amarelecimento do verniz e da cera-resina, bem como o contraste entre as áreas brilhantes e opacas destas camadas, estavam dando um aspecto pouco homogêneo à pintura.

Na faixa horizontal central da obra, nas áreas do céu com coloração azul claro e branca, observaram-se alterações na pintura. Nestes locais, parecem ter ocorrido abrasões da camada pictórica, deixando parte da camada de preparação branca aparente [figura 6]. No quadrante superior esquerdo, na parte escura do céu, observou-se uma alteração similar. É bastante provável que estas zonas de branqueamento e abrasão das camadas de pintura superficiais tenham sido provocadas por uma limpeza agressiva no passado, utilizando métodos inadequados como soluções decapantes ou muito penetrantes, junto com uma ação mecânica insistente. Observaram-se também retoques anteriores visíveis nas imagens LUV e a olho nu, localizados nas laterais da pintura.

Por fim, "Enterro na Rede" encontrava-se em pior estado de conservação, tanto do ponto de vista estrutural como estético. Em relação à estrutura, o reentelamento de 1969 tinha sido realizado de forma inapropriada, ocasionando diversas alterações na obra. A tela apresentava numerosas deformações redondas, de distintos tamanhos, distribuídas de forma aleatória por toda a superfície [figura 7]. Estas deformações comprometiam a estabilidade estrutural do suporte no futuro e o aspecto da obra.

Não é mencionada na ficha técnica de 1969 nenhuma justificativa sobre as razões da intervenção. Pelo contrário, na ficha consta "pintura em bom estado, sem rachaduras ou outras falhas" (Bettencourt 1969). É provável que o 


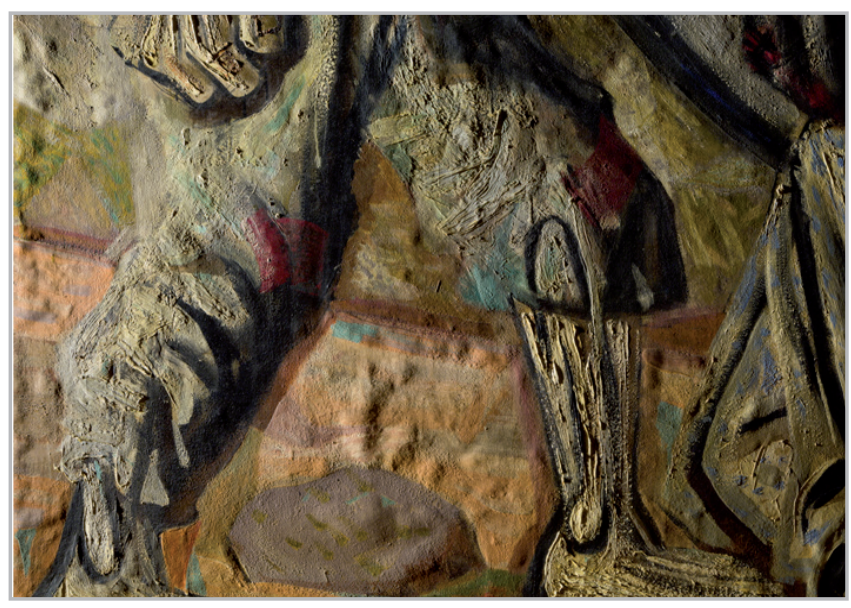

Figura 7.- Detalhe das bolhas em "Enterro na Rede" na fotografia LR. Fotos: Pedro Campos/Elizabeth Kajiya/Márcia Rizzuto (IFUSP).

reentelamento tenha sido realizado para reforçar a pintura, como intervenção mais preventiva do que curativa, como era habitual até os anos 70-80 (Westby 1974; Ackroyd 2002; Villers 2003). Portanto, é muito provável que as bolhas tenham aparecido após a intervenção. Efetivamente, a tela escolhida para o reentelamento é inadequada, pois é muito mais espessa, grossa e com uma densidade (fios/cm2) bem menor do que da tela original, que é muito mais fina e densa. Por ter características tão distintas, a tela auxiliar reage às diferenças climáticas de uma forma completamente diferente, impondo grandes tensões mecânicas a tela original. Além disso, a aplicação da cera-breu foi realizada de forma heterogênea, deixando algumas zonas com excesso e outras com falta de adesivo, comprometendo a adesão integral entre as duas telas. É provável que a cera-resina tenha se degradado, como tinha sido indicado por Barbosa (2012), pois foram observadas zonas de cera-resina com pouca aderência. Igualmente, a temperatura do tratamento parece ter sido excessiva, queimando parcialmente certas zonas da camada pictórica, ressecando-a e sensibilizando parte do verniz, permitindo uma fusão entre este e a cerabreu.

Em consequência deste tratamento, a camada pictórica se tornou frágil e quebradiça. Por um lado, as diferenças nos comportamentos higrométricos e nas elasticidades entre a tela original e a tela de reentelamento, provocaram tensões mecânicas em todos os estratos pictóricos. Por outro lado, solicitada pelas tensões, a camada pictórica perdeu parte da sua elasticidade original, levando à formação de craquelês e levantamentos na pintura, documentados em 1992, 2012 e no momento da realização do diagnóstico, em 2018. Esta fragilidade, entre outras razões, contribuiu com a decisão de deixar a obra na Reserva Técnica nos últimos anos.

Quanto a camada de verniz, esta encontrava-se bastante escurecida e suja, e bastante mais oxidada, aparecendo mais verde e opaca que nas outras duas obras nas fotografias LUV (De la Rie 1982) [figura 5]. O aspecto ótico da obra encontrava-se demasiado brilhante, algo atípico da técnica do artista neste período. O resultado estético geral era bastante heterogêneo, devido à presença de restos e acúmulos amarelados de cera-resina. O envelhecimento da camada de verniz e da cera-breu alteravam, em consequência, a aparência da obra. Devido ao envelhecimento destes substratos, "Enterro na Rede"por si só já diferente das outras duas pinturas no que diz respeito às suas características estilísticas -destoava ainda mais do conjunto.

\section{Tratamento de conservação e restauro}

O tratamento foi decidido com dois objetivos principais: por um lado, era necessário estabilizar as alterações presentes para assegurar uma boa conservação das obras no futuro; por outro lado, era importante melhorar a homogeneidade das pinturas, para assegurar um equilíbrio estético entre as três obras da série. Assim, as três foram tratadas sempre visando uma coerência, tanto em termos da escolha dos materiais de restauro, como na escolha dos níveis de intervenção.

Em "Criança Morta", foi decidido realizar tratamentos pontuais e mínimos, tendo em conta o bom estado geral da obra. A maior alteração era a presença de marcas de fungos tanto no verso, como na face da pintura. Era, portanto, crucial resolver essa questão para evitar futuros danos e para melhorar o aspecto estético da obra. Primeiramente, uma limpeza geral a seco com aspirador equipado com filtro HEPA, seguido de uma limpeza com misturas de etanol a $30 \%$ e $40 \%$ em solventes alifáticos, permitiu tratar os fungos, reduzindo o risco de proliferação futura (Stavroudis 2013; Florian 2002). Um maior controle das condições climáticas deverá, no entanto, ser realizado para evitar uma futura reativação dos microorganismos. Ao mesmo tempo, esta intervenção permitiu retirar os retoques visíveis e reduzir de forma equilibrada a quantidade de verniz presente na obra, instituindo uma maior homogeneidade na limpeza da obra.

Em "Retirantes", a maior alteração era o envelhecimento do verniz, da cera-resina e dos retoques de 1962 . O processo de remoção do excesso de cera-resina foi feito com raspagem manual pelo verso e com misturas de solventes orgânicos pela frente, conjuntamente à limpeza do verniz e dos retoques visíveis.

A planificação dos craquelês e das ondulações presentes no suporte foi feita na mesa térmica com vácuo. Foi adicionada uma pressão mecânica através de espátulas e rolos para xilogravuras. Em alguns pontos, onde o processo não se mostrou suficiente, uma espátula térmica foi usada. O processo permitiu a reativação e distribuição homogênea da cera-resina no verso e a planificação dos craquelês e das deformações.

Como o chassi presente nesta obra é possivelmente original, optou-se por adaptá-lo para torná-lo móvel, através de cunhas, e mais estável, com uma trave em cruz. A tela foi grampeada no chassi sobre fita de algodão para facilitar 
futuros tratamentos, sem danificar a tela. A montagem da tela no chassi e o ajuste da tensão por meio das cunhas, permitiu melhorar a tensão geral e o nivelamento da tela.

Em "Enterro na Rede" era necessário restabelecer uma estabilidade estrutural, tratando os levantamentos da camada pictórica e as bolhas. Primeiro, as zonas de levantamento foram consolidadas utilizando cera de abelha clarificada, escolhida pela sua compatibilidade material com o reentelamento. A tela foi em seguida removida do chassi e o excesso de cera-resina do verso e das bordas foi reduzida de forma mecânica. Para tratar as deformações e bolhas existentes, foi feito um tratamento com pressão e calor, utilizando a mesa térmica com vácuo. Por conta das dimensões da obra, o processo foi feito em várias etapas.

A temperatura possibilitou a reativação das propriedades da cera-resina permitindo a sua distribuição homogênea pelo verso, resultando numa planificação geral e a re-adesão das zonas de suporte descoladas. Para assegurar a adesão das zonas com falta de adesivo, foi aplicada pontualmente cera de abelha clarificada adicional. No entanto, várias deformações persistiram, sendo necessário o uso de peso, para ajudar na planificação, e da espátula térmica, para uma ação de calor/pressão maior, mais localizada. O tratamento permitiu a eliminação das bolhas, melhorando a estabilidade estrutural e o aspecto visual da obra, mas ficaram algumas deformações pontuais. Discussões foram necessárias nesse momento para reavaliar as opções de tratamento, pois a persistência das bolhas podia comprometer a estabilidade da obra no futuro. Avaliou-se a possibilidade de eliminar o reentelamento e de trazer outras opções de reforço estrutural (reforço de bordas, reentelamento com adesivos sintéticos, reentelamento solto, etc. (Bustin e Caley 2003; Villers 2003; Heiber et al. 2012). Não obstante, foi decidido conjuntamente manter a tela de reentelamento, pois sua remoção poderia colocar em risco os estratos pictóricos, já fragilizados. Além disso, as deformações já não perturbavam o aspecto geral da obra, sendo pontuais e menos proeminentes, e não foram observadas outras alterações estruturais que viessem justificar um tratamento de suporte mais intervencionista. Portanto, foi decidido aceitar os limites do tratamento, com a condição de realizar um monitoramento regular da obra, de forma a avaliar a evolução das deformações e detectar qualquer mudança. Assim, na existência de algum problema no futuro que venha a prejudicar a estabilidade da obra, novas alternativas de tratamento poderão ser avaliadas, tendo em conta o desenvolvimento de pesquisas relacionadas, por exemplo pelo projeto Conserving Canvas (2020).

A tela foi esticada no chassi da mesma forma descrita para "Retirantes". Em seguida, removeu-se novamente o excesso de cera-resina na face da pintura graças à uma limpeza da superfície pictórica com solventes orgânicos.

Uma das principais dificuldades no tratamento foi a limpeza da camada pictórica das três obras, que tinha como objetivo encontrar o equilíbrio estético, tendo em conta os diferentes níveis de limpeza. Para encontrar uma coerência visual, foi tomada como referência "Criança Morta", que é a obra que se encontrava mais limpa e mais homogênea das três. Foram realizados protocolos de testes baseados nas metodologias de trabalho elaboradas por Cremonesi $(2011$; 2012; 2014) e Wolbers (2013), para encontrar soluções de limpeza adequadas. Era necessário realizar uma limpeza controlada e progressiva da camada pictórica, evitando qualquer dano ou alteração dos estratos pictóricos. Efetivamente, durante a realização dos testes, foi observada a sensibilidade de certos pigmentos aos solventes polares. Sendo relativamente recentes, é possível que as camadas pictóricas não tenham tido tempo de polimerizar totalmente e gerar uma resistência maior (Phenix 2001; Doucet 2002, Phenix et al. 2012), o que explicaria inclusive as limpezas parciais e seletivas realizadas no passado, no caso de "Retirantes" e "Criança Morta", pois é provável que uma limpeza total e homogênea não fosse possível.

Em “Criança Morta"e "Retirantes", as cores marrons, pretas e azuis demonstraram-se bastante sensíveis. Tendo em conta a fragilização dos estratos pictóricos durante o tratamento de reentelamento, "Enterro na Rede" apresentava uma fragilidade ainda maior, especialmente nos azuis, marrons, vermelhos e verdes. Esta sensibilidade necessitava uma flexibilidade e uma atenção particular ao longo de toda a limpeza, pois era necessário adaptar a técnica da aplicação do solvente em função da sensibilidade da zona e do acúmulo das resinas e ceras superficiais.

No caso de "Retirantes", o processo de limpeza geral foi feito com misturas de etanol a 30\% e $40 \%$ em aguarrás mineral. Em áreas com cores mais sensíveis, ou apresentando acúmulos de cera-resina maiores, e nas áreas com retoques anteriores alterados, as misturas de solventes foram aplicadas com compressas de papel japonês, permitindo reduzir a ação mecânica e a evaporação do solvente, otimizando a ação de limpeza. Nas áreas da pintura com relevos e texturas de difícil acesso para os cotonetes foram utilizadas mesmas misturas de solventes em gel de ácido poliacrílico (Carbopol ${ }^{\circledR}$ e Pemulen ${ }^{\circledR}$ ) (Dupuy 2012; Cremonesi 2012; Phenix 2012; Wolbers 2013; Cremonesi 2014; Hennen et al. 2017), aplicado com pincel, e removidos com uma mistura menos polar. No caso dos resíduos pontuais de verniz antigo e cera-resina incrustados na pintura, foi possível a remoção pontual com bisturis, após o amolecimento com solventes ou géis.

No caso de "Enterro na Rede" o verniz oxidado e a ceraresina na camada pictórica - que não tinham sido limpos no passado - foram reduzidos, pois a remoção total teria prejudicado os pigmentos sensíveis. Misturas de etanol a $70 \%$ e $80 \%$ em aguarrás mineral foram aplicadas sobre compressas de papel japonês e logo removidos com uma mistura de solventes com mesma ou menor polaridade, em função da quantidade de resina presente na zona. A remoção foi feita rolando cuidadosamente o cotonete sobre a superfície da pintura, especialmente nas cores mais 
sensíveis, nas zonas pulverulentas e nas zonas com textura, tentando diminuir as possíveis abrasões na camada pictórica. A limpeza foi feita de forma uniforme por toda a face, mas com menor insistência nas zonas frágeis.

Após os processos de limpeza, novas imagens LUV foram realizadas para registrar o nível de limpeza das obras e ajudar futuros tratamentos de restauro [figura 5]. Nestas fotografias, a mudança na fluorescência das pinturas depois da intervenção demonstra uma redução homogênea do verniz. A limpeza permitiu também uma mudança cromática surpreendente em "Enterro na Rede", na qual recuperou-se a intensidade das cores [figura 8-9].

A reintegração cromática e a aplicação da camada de proteção também foram decididas em função do aspecto final das três obras.
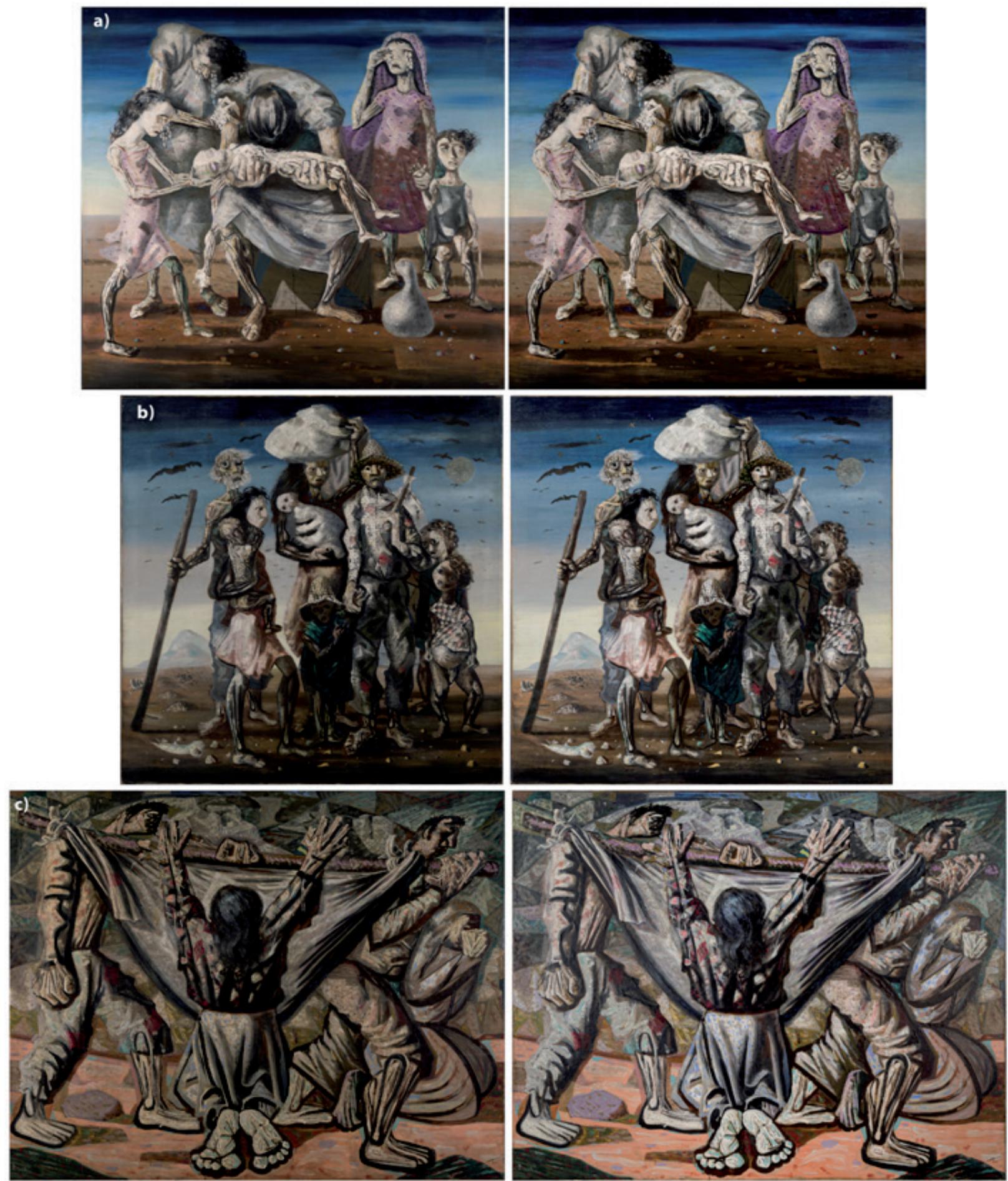

Figura 8.- Fotografia LV antes (esq.) e depois (dir.) do tratamento de conservação e restauro de: a) “Criança Morta”; b) “Retirantes"; c) “Enterro na Rede". Fotos: Pedro Campos/Elizabeth Kajiya/Márcia Rizzuto (IFUSP). 


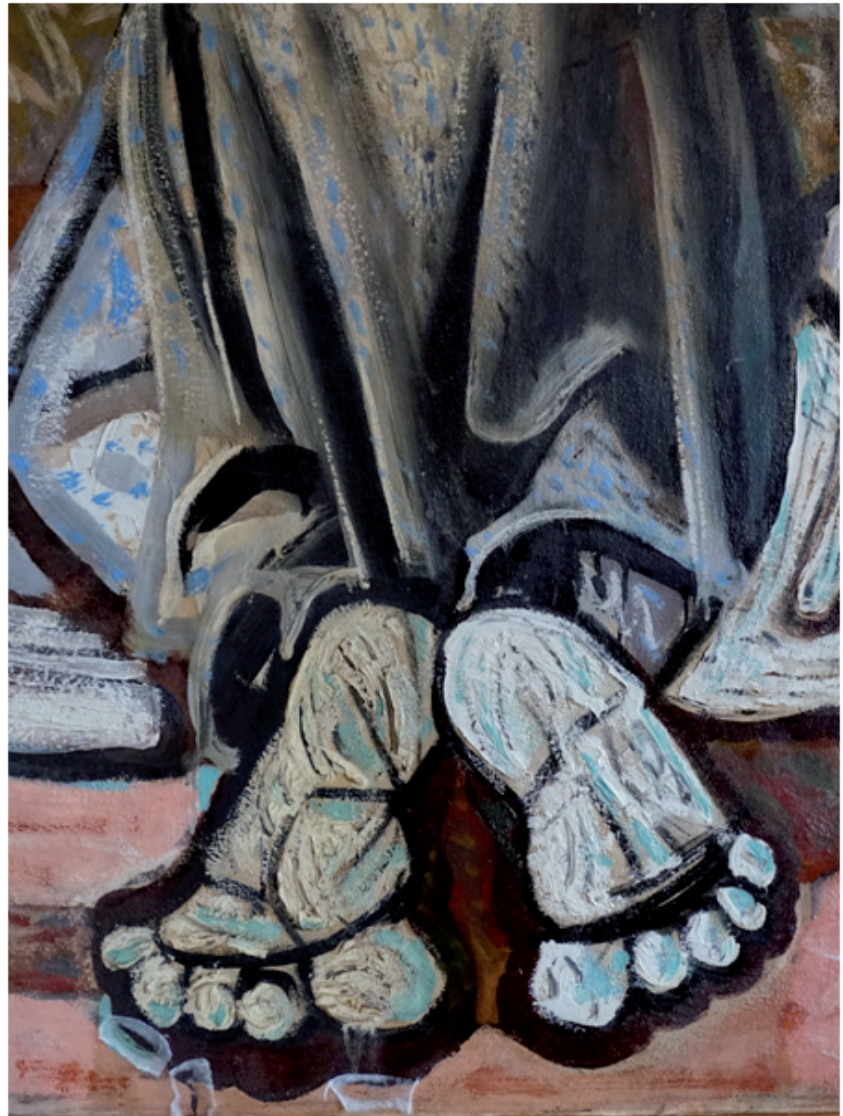

Figura 9.- Detalhe durante a limpeza de "Enterro na rede" com LV: o pé direito e a parte esquerda da saia foram limpadas. Fotos: Pedro Campos/Elizabeth Kajiya/Márcia Rizzuto (IFUSP).

Uma camada de Regalrez ${ }^{\circledast} 1094$ a 40\% em aguarrás mineral foi aplicada com trincha sobre toda a superfície pictórica de forma a proteger a pintura. O Regalrez ${ }^{\circledR}$ foi escolhido por ser uma resina sintética de baixo peso molecular, muito estável no tempo, resistente à oxidação e, sobretudo, bastante reversível, pois permanece solúvel em solventes pouco polares (De la Rie e McGlinchey 1990; McGlinchey 1990; Leonard 1990, Whitten 1995; De la Rie 2003, Mariotti e Borgioli 2004; Von der Goltz et al. 2012), permitindo uma limpeza muito fácil, o que evitará tratamentos futuros que possam sensibilizar novamente os pigmentos originais.

A reintegração cromática foi realizada com tintas de restauro Gamblin ${ }^{\circledR}$ Colors. A base de resina sintética de baixo peso molecular, Laropal ${ }^{\circledR} \mathrm{A} 81$, e pigmentos triturados industrialmente, estas tintas são de fácil aplicação, resistentes e estáveis (De la Rie et al. 1995; Dunkerton 2010). Translúcidas e finas, permitem retoques muito sutis, especialmente indicados para veladuras e retoques de acabamento. As tintas permitiram um trabalho delicado nas zonas de manchas de fungos, retoques antigos e desgastes.

Após os retoques, foi realizada a pulverização de Regalrez ${ }^{\circledast}$ 1094 a 10\% em aguarrás com adição de 2 e 3\% de cera microcristalina, para obter um resultado ótico final mais acetinado, correspondendo ao aspecto das obras de Portinari.

\section{Conclusão}

O projeto de estudo, conservação e restauro das três obras de Portinari da série "Retirantes", reuniu curadores, conservadores-restauradores e cientistas do museu e externos. Os exames a olho nu e as análises científicas permitiram comparar a tecnologia, matérias e procedimentos artísticos das três obras, avaliando similaridades e diferenças do suporte, desenho, camada de preparação e camada pictórica. Os resultados destas análises permitiram trazer informações relevantes e novas, importantes para o conhecimento da técnica e da obra do artista Candido Portinari, uns dos mais importantes na tradição artística brasileira.

Estas observações possibilitaram também avaliar o estado de conservação das três obras, a fim de definir um tratamento adequado, que se adaptasse às necessidades específicas de cada uma, mas que admitisse ao mesmo tempo, reencontrar uma unidade estética entre as três obras. O tratamento permitiu estabilizar as três obras e resolver problemas estruturais que podiam comprometer a conservação das obras no futuro, especialmente no caso de "Enterro na Rede". A limpeza, a reintegração cromática e a aplicação de vernizes novos, melhorou o estado estético das pinturas - que mostravam aspectos bastante diferentes devido aos distintos níveis de intervenção obtidos no passado - alcançado assim um resultado ótico homogêneo entre as três obras [figura 9]. Este equilíbrio reestabeleceu uma coerência estética, mais próxima da intenção inicial do artista, cumprindo também o objetivo de apresentação enquanto "tríptico", com o qual as obras foram adquiridas para o museu.

Por fim, este trabalho mostra, por um lado, a importância da integração nos projetos de conservação e restauro de estudos aprofundados implicando diferentes especialistas, incluindo análises científicas e favorecendo a discussão interdisciplinar. Por outro lado, é demonstrada a importância - quando se trata de obras que são parte de uma mesma série - da definição de tratamentos que considerem as obras como um conjunto e que sejam coerentes, respeitando a unidade histórica e estética das obras. O tratamento de conservação e restauro levou em conta, ainda, os restauradores do futuro, deixando não só a documentação e análises detalhadas, mas também uma abertura a novas possibilidades de tratamento.

\section{Agradecimentos}

Os autores gostariam de agradecer especialmente a todos os profissionais das áreas de Acervo e Curadoria do MASP, que contribuíram na realização deste projeto e que acompanharam de perto todas as etapas deste trabalho. Os autores gostariam também de agradecer a todos os profissionais de outros museus e instituições, públicas e privadas, que participaram das apresentações e debates realizados pelas equipes durante o processo, antes e despois do tratamento de conservação e restauro. 


\section{Referências}

ACKROYD, P. (2002). “The Structural Conservation of Canvas Paintings: Changes in Attitude and Practice Since the Early 1970s", Studies in Conservation, 47 (Supplement 1): 3-14. https://www.tandfonline.com/ doi/abs/10.1179/sic.2002.47.Supplement-1.3. [consulta:01/06/2021].

BARDI, P.-M. (1985). Portinari [catálogo de exposição]. Curitiba: Clube Curitibano.

BARBOSA, K. (2012). Relatório de intervenção. Arquivos do MASP.

BETTENCOURT, O. (1969). Ficha técnica. Arquivos do MASP.

BRIXA, T. (1991). Orçamento e Proposta de tratamento. Arquivos do MASP.

Conserving Canvas. The Getty Foundation. (2020). https://www. getty.edu/foundation/initiatives/current/conservingcanvas/ index.html. [consulta: 01/06/2021]

BUSTIN, M. e CALEY T. (2003). Alternatives to lining: the structural treatment of paintings on canvas without lining: a Conference Held Jointly by the British Association of Paintings Conservator-Restorers and the United Kingdom Institute for Conservation Paintings Section. United Kingdom Institute for Conservation.

CREMONESI, P. (2011). El ambiente acuso para el tratamiento de obras polícromas. Padova: II Prato.

CREMONESI, P., e SIGNORINI, E. (2012). Un approccio alla pulitura dei dipinti mobili, Padova: II Prato.

CREMONESI, P. (2014). L'uso dei solventi organici nella pulitura di opere policrome. Padova: II Prato.

DE LA RIE, E.R. (1982). "Fluorescence of Paint and Varnish Layers (Part II)". Studies in Conservation, 27: 65-69. https://doi. org/10.1179/sic.1982.27.2.65

DE LA RIE, E.R. e MCGLINCHEY, C.W., (1990). "New synthetic resins for picture varnishes". Studies in Conservation, 35: 168-173. https:// doi.org/10.1179/sic.1990.35.s1.036.

DE LA RIE, E.R., LOMAX, S.Q., PALMER, M., GLINSMAN L.D. e MAINES, C.A. (1995). "An investigation of the photochemical stability of urea-aldehyde resin retouching paints: Removability tests and colour spectroscopy". Studies in Conservation, 45:51-59. https://doi. org/10.1179/sic.2000.45.Supplement-1.51

DE LA RIE, E.R. (2003). "Why use a synthetic picture varnish?". Em Actes du congrès. Art et Chimie: les polymères, Paris: CNRS Editions, 63-68.

DIGNEY-PEER, S., THOMAS, K., PERRY, R., TOWNSEND, J., GRITT, S. (2012). "The imitative retouching of easel paintings". Em The Conservation of Easel Paintings, Stoner, J.H., Rushfield, R. (coord.), Londres, New York: Routledge. https://doi. org/10.4324/9780429399916-43.
DOUCET, S. (2002). "Étude de l'action des solvants organiques sur la couche picturale des peintures à I'huile". ARAAFU. Conservation-Restauration des Biens Culturels, 19/20: 65-68.

DUNKERTON, J. (2010). "Retouching with Gamblin Conservation Colours". Em Mixing and Matching, Ellison, R., Smithen, P., Turnbull, R. Londres: Archetype Publications.

DUPUY, C. (2012). “Les solvants organiques neutres épaissis pour le nettoyage d'une couche picturale". CeROArt: EGG 2. https:// doi.org/10.4000/ceroart.2634.

FLORIAN, M.-L.E. (2002). Fungal Facts: Solving fungal problems in heritage collections. Londres: Archetype Publications.

GORINI, E. (2017). Um museu vivo de percurso inovador. MASP [catálogo]. São Paulo, Brasil: Museu de Arte de São Paulo, J. Safra Instituto Cultural, 19-26.

HEIBER, W., TOMKIEWICZ, C., SCHARFF, M., LEVENSON, R. (2012). "Tear mending and other structural treatments of canvas paintings, before or instead of lining". Em The Conservation of Easel Paintings, Stoner, J.H., Rushfield, R. (coord.), Londres, New York: Routledge. https://doi.org/10.4324/9780429399916-29 [consulta: 01/06/2021].

HENNEN, S., MEDEROS-HENRY, F., DE BOULARD, C., ESPINOSA, M.F., CREMONESI, P. (2017). "A study on the influence of organic and inorganic alkali on the formulation and properties of Pemulen TR-2 gels". Em: Gels in Conservation Conference, The Emmanuel Centre, Tate Museum, London. https://www.youtube.com/ watch?v=jsxjV7gC1zY [consulta: 01/06/2021].

LEONARD, M. (1990). "Some observations on the use and appearance of two new synthetic resins for picture varnishes". Studies in Conservation, 35: 174-176. https://doi.org/10.1179/ sic.1990.35.s1.037.

MARIOTTI, P., BORGIOLI, L. (2004). "Applicazione di nuove vernici ad alta stabilità". Em: // Congresso Nazionale IGIIC: Lo stato dell'arte, 470-476.

MASP (2008). Brazilian Art. American Art. Donations and Collections, 3 [Catálogo de museu], São Paulo: Museu de Arte de São Paulo.

MCGLINCHEY, C.W. (1990). "The industrial use and development of low molecular weight resins: an examination of new products of interest to the conservation field". Em: ICOM Committee for Conservation, 9th triennial meeting, Dresden, 563-567.

Museu Casa de Portinari, Brodowski, Brasil. https://www. museucasadeportinari.org.br [consulta: 28/01/2021].

PEDROSA, A., PROENÇA, L. (2015), Concreto e Cristal: O acervo do MASP nos cavaletes de Lina Bo Bardi. São Paulo: Cobogó - MASP.

PENNA, C.S.G., PORTINARI, J.C. (2004), Candido Portinari. Catálogo Raisonné, vol.2 (1939 - 1944), Projeto Portinari, Rio de Janeiro. 
PHENIX, A. (2001). "Swelling of artists' oil paints due to sorption of organic solvents". The Picture Restorer, 20: 16-19. https://doi. org/10.1179/019713602806082647

PHENIX A., WOLBERS, R.C., TOWNSEND, J., ZUMBÜHL, S., BARTOLETTI A., LEE J., ORMSBY, B. (2012). "Removal of varnish: organic solvents as cleaning agents". Em The Conservation of Easel Paintings, Stoner, J.H., Rushfield, R. (coord.), London, New York, Routledge. https://doi.org/10.4324/9780429399916-37

Projeto Portinari. http://www.portinari.org.br/. [consulta: 28/01/2021].

RESCALA, J.J. (1962). Ficha de tratamento. Arquivos do MASP.

ROSADO, A., MENDES, I., MOTTA JR, E., TEIXEIRA, C.V., SOUZA, L.A.C. (2011), "Candido Portinari, Materials and Techniques of a Brazilian Modern Painter - Part I". Em ICOM CC 16th Trienal Conference Lisbon, Lisboa, 1-9.

ROSADO, A., MENDES, I., MOTTA JR, E., TEIXEIRA, C.V., SOUZA, L.A.C. (2014), "Material and technical studies of a selected group of paintings by Candido Portinari, a major Brazilian Modernist Painter". Em Science and Art: the Painted Surface, London, Royal Society of Chemistry, 460-474.

STAVROUDIS, C. (2013). "Superstorm Sandy: Frontline Advice for Dealing with Mold and Salvaging Electronic Devices". Em: WAAC Newsletter, vol. 35;1.

TEIXEIRA, C.V., MOTTA, E., GRAÇA, M.C., CARVALHO, H.E., SOUZA, L.A.C (2011) "O restauro dos painéis 'Guerra e Paz' de Candido Portinari". Em I Encontro Luso-Brasileiro de Conservação e restauro, 196-206.

VILLERS, C. (2003). Lining paintings: papers from the Greenwich Conference on Comparative Lining Techniques. London: Archetype.

VON DER GOLTZ, M., PROCTOR, R.G., WHITTEN, J., MAYER, L., MYERS, G., HOENIGSWALD, A., SWICKLIK, M. (2012). "Varnishing as part of the conservation treatment of easel paintings". Em The Conservation of Easel Paintings, Stoner, J.H., Rushfield, R. (coord.), London, New York: Routledge, 635-658. https://doi. org/10.4324/9780429399916-44.

WESTBY, P.-P. (1974). The Lining Cycle: Fundamental causes of deterioration in painting on canvas: materials and methods of impregnation and lining from the 17th century to the present day, Londres: National Maritime Museum.

WHITTEN, J. (1995). “Regalrez 1094: Properties and uses”, WAAC Newsletter, 17: 11-12.

WOLBERS, R. (2013). Le nettoyage des surfaces peintes. Méthodes aqueuses. Paris: Eyrolles.

\section{Autor/es}

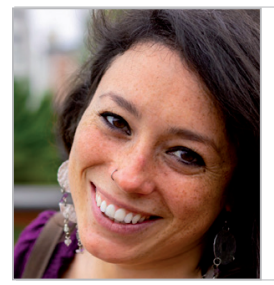

\section{Sofia Hennen Rodriguez}

sofia.hennen@masp.org.br

Museu de Arte de São Paulo Assis

Chateaubriand - MASP (Brasil)

Sofia Hennen formou-se na Bélgica, em História da Arte, na Universidade Libre de Bruxelas (ULB), com mestrado em pintura flamenca, e em Conservação e Restauro de Pinturas, pela Escola Nacional Superior das Artes Visuais (ENSAV), com bacharelado e mestrado em ambas as instituições. Durante seus estudos de conservação e restauro, Sofia se especializou nas técnicas e soluções de limpeza de obras policromadas, especialmente na aplicação de géis policacrílicos. Teve várias experiências profissionais em distintos museus e instituições culturais no Chile, Espana e Bélgica, como uma prática de aperfeiçoamento no Instituto Real do Patrimônio Artístico Belga (KIK-IRPA). Durante sua carreira, tem se especializado na conservação e restauro de pinturas sobre tela, cobre e madeira. Atualmente, ela é responsável pela área de conservação e restauro do Museu de Arte de São Paulo (MASP), onde tem estabelecido metodologias e protocolos de pesquisa, conservação e restauro, e vem organizando projetos interdisciplinares com professionais e instituições nacionais e internacionais.

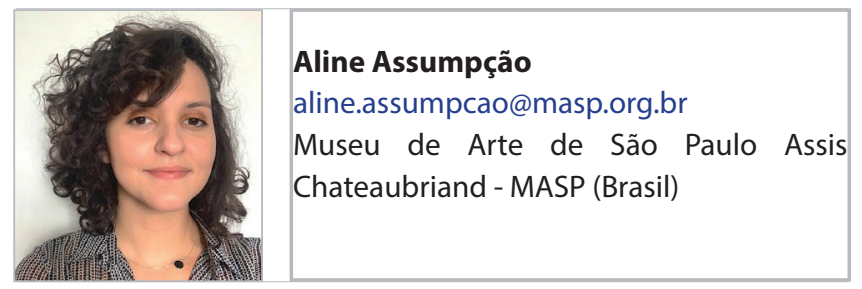

Aline Assumpção obteve seu bacharelado em Conservação e Restauro pela Universidade Federal do Rio de Janeiro em 2017, e é atualmente mestranda em ciências da conservação e restauro de arte contemporânea, pela Universidade de Lisboa. Seu projeto de estudo baseia-se em um estudo comparativo de géis e emulsões na limpeza de pinturas acrílicas. Ao longo de sua formação, Aline realizou estágios e participou de projetos em instituições brasileiras e portuguesas, além da contribuição com o grupo Sustainability in Conservation, que visa projetos voltados para a sustentabilidade aplicada à conservação e restauro. Atua desde 2020 como assistente de conservação e restauro no Museu de Arte de São Paulo (MASP), onde contribui para a pesquisa e atividades de conservação e restauro da instituição.

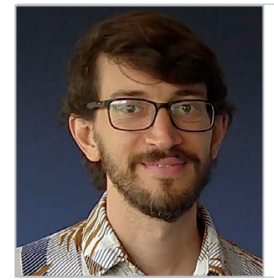

\section{Pedro de Campos}

pcampos@usp.br

Laboratório de Arqueometria e Ciências Aplicada ao Patrimônio Cultural (LACAPC), Universidade de São Paulo (USP), (Brasil)

Pedro de Campos é especialista em analises por imageamento e físico-químicas de objetos do Patrimônio Cultural. Possui 
bacharelado e licenciatura em Física pela Unicamp, e mestrado e doutorado em Física pela Universidade de São Paulo (USP). Atual na área da Ciência do Patrimônio desde 2005. Desde 2018, é pesquisador de pós doutorado na Universidade de São Paulo, participando de estudos dos acervos dos museus da USP e no desenvolvimento de novas técnicas analíticas voltadas a pesquisa em bens do Patrimônio Cultural.

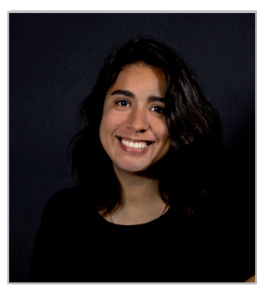

\section{Bianca Gonçalves}

bianca.ds.goncalves@gmail.com

3e Louise Colignystraat, Den Haag, Netherlands

Bianca Gonçalves licenciou-se em Conservação e Restauro em 2013 pelo Instituto Politécnico de Tomar, Portugal. Em seguida, fez especialização em conservação e restauro de pinturas em ENSAV La Cambre, Bruxelas. Na sua tese de mestrado, Bianca explorou abordagens menos tóxicas para a limpeza de pinturas acrílicas convergindo o seu interesse em Sustentabilidade, Química Verde e Conservação e Restauro. Durante os seus estudos, estagiou e trabalhou em ateliês privados e museus em Portugal, Bruxelas, Malta e Itália. Até 2019 trabalhou no Museu de Arte de São Paulo (MASP) no Brasil como conservadora-restauradora com foco em conservação preventiva e exposições temporárias. Atualmente trabalha no Studio Redivivus na Holanda, onde está principalmente em contato com pinturas modernas, contemporâneas e suporte de madeira.

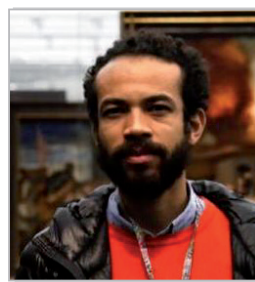

\section{Erick Santos}

erick.santos@masp.org.br

Museu de Arte de São Paulo Assis Chateaubriand - MASP, (Brasil)

Erick Santos de Jesus, é especialista na área de conservação de Bens do Patrimônio Histórico Cultural. Bacharel em Artes Plásticas pela Universidade Braz Cubas (2007). Especialização/ Master em conservação e restauro de obras de arte moderna e contemporânea (Universidade Complutense de Madrid, 2012). Desde 2004 trabalha como assistente no Núcleo de Acervo, Conservação e Restauro do Museu de Arte de São Paulo -MASP.

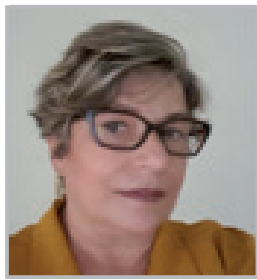

\section{Elizabeth A. M. Kajiya}

elizabethkajiya@gmail.com

Laboratório de Arqueometria e Ciências Aplicada ao Patrimônio Cultural (LACAPC), (Brasil)

Elizabeth A. M. Kajiya, é especialista e atua na área de análises por imageamento em Bens do Patrimônio Histórico Cultural. Bacharel em Comunicação Visual pela Faculdade de Belas Artes de São Paulo (1988). Especialização em conservação/restauração de obras de arte em pinturas de cavalete e esculturas policromadas (Instituto Paulista de Restauro, 1998).Desde 2007 tem contribuído no desenvolvimento de pesquisas no Instituto de Física da Universidade de São Paulo, com técnicas não-destrutivas por meio de imageamento multiespectrais em Patrimônio Cultural, em colaboração com Museus Paulistas. Especialização em perícia grafotécnica (Conselho Nacional dos Peritos Judiciais da República Federativa do Brasil, 2012).

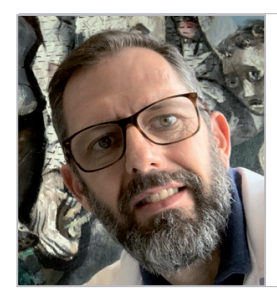

\section{Fábio Luchiari}

fabioluchiari@hotmail.com

Museu de Arte Contemporânea de Americana e Museu Histórico Pedagógico

Fábio Luchiari é conservador e restaurador de pintura de cavalete no Ateliê De Vera Artes - Restauração de Obras de Artes. Especialista em Museologia, Colecionismo e Curadoria pelo Centro Universitário Belas Artes de São Paulo, Bacharel em Administração e Restaurador Conservador pelo Instituto Paulista de Restauro. Foi coordenador de museus pela Prefeitura de Americana de 1997 a 2003 (Museu de Arte Contemporânea de Americana e Museu Histórico Pedagógico)

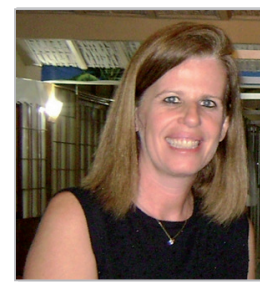

\section{Márcia de Almeida Rizzutto}

rizzutto@if.usp.br

Laboratório de Arqueometria e Ciências Aplicada ao Patrimônio Cultural (LACAPC), (Brasil)

Bacharel e Licenciada em Física. Mestre e Doutora em Física com especialização em Física Nuclear. Pós-doutoramento em Física Aplicada ao Estudo do Patrimônio Histórico e Cultural na Universidade de Sassari, Itália (2008). É professora livre-docente do Instituto de Física da Universidade de São Paulo (IF-USP) desde 2001 no Departamento de Física Nuclear. É orientadora nos cursos de pós-graduação da USP na área de Física e de Museologia. Desenvolve pesquisas relacionadas à caracterização de materiais, principalmente de estudos e análises de objetos do patrimônio Histórico e Cultural (Arqueometria), em parcerias com os museus da USP e do Estado de São Paulo. Coordena o Laboratório de Arqueometria e Ciências Aplicadas ao Patrimônio Cultural do Instituto de Física da USP - LACAPC-IFUSP (https://portal.if.usp. br/arqueometria/pt-br/laboratorio) e também coordena o Núcleo de Pesquisa de Física Aplicada ao Estudo do Patrimônio Artístico e Histórico (NAP-FAEPAH) da Pró-Reitoria de Pesquisa da Universidade de São Paulo (http://portal.if.usp.br/faepah/pt-br).

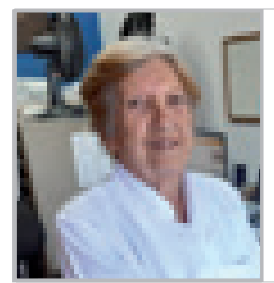

\section{Florence White de Vera}

de.veraartes@terra.com

Museu de Arte Contemporânea da USP

Florence Maria White de Vera, conservadora/restauradora de pinturas. Formada em História pela Universidade de São Paulo 
e em Pintura de cavalete pelo Instituto Paulista de Restauro. Conservadora Restauradora no Museu de Arte Contemporânea da USP, afastando-se por aposentadoria em 1997, ano em que fundou a empresa DE VERA ARTES, com equipe especializada em restauração de pinturas, obras de arte em papel e imagens sacras. Neste período foram concretizados projetos importantes junto ao IPHAN, secretaria de Cultura do Estado de SP e de instituições bancárias, museus, galerias e colecionadores particulares.

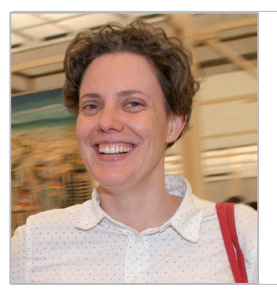

\section{Cecilia Winter}

mcwinter@gmail.com

Managing Collections Environments do Getty Conservation Institute, Los Angeles

Cecilia Winter é especialista em museologia pelo Curso de Especialização em Museologia da Universidade de São Paulo e conservadora-restauradora com graduação e mestrado pela Universidade Paris 1 Panthéon Sorbonne, Paris. Atua na área de conservação preventiva de exposições e coleções desde 2004. Atuou na coordenação do núcleo de Acervo, Conservação e Restauro entre 2015 e 2020. Em 2021 passou a integrar a equipe da iniciativa Managing Collections Environments do Getty Conservation Institute, Los Angeles 